\title{
Conspecific cues encourage Barn Swallow (Hirundo rustica erythrogaster) prospecting, but not nesting, at new nesting structures
}

\author{
Andrew J. Campomizzi ${ }^{1}$, , Zó M. Lebrun-Southcott ${ }^{1}$, and Kristyn Richardson ${ }^{2}$ \\ ${ }^{1}$ Bird Ecology and Conservation Ontario, 114 Vaughan Road, Suite 307, Toronto, Ontario M6C 2M1 Canada \\ ${ }^{2}$ Bird Studies Canada, P.O. Box 160, 115 Front Street, Port Rowan, Ontario N0E 1M0 Canada \\ *Corresponding author: andy@beco-birds.org
}

Campomizzi, A.J., Z.M. Lebrun-Southcott, and K. Richardson. 2019. Conspecific cues encourage Barn Swallow (Hirundo rustica erythrogaster) prospecting, but not nesting, at new nesting structures. Canadian Field-Naturalist 133(3): 235-245. https://doi.org/10.22621/cfn.v133i3.2233

\begin{abstract}
Shed-like structures are being built to provide Barn Swallow (Hirundo rustica erythrogaster) nesting habitat in response to population declines. However, Barn Swallow use of these structures is unavailable in the literature. We conducted three manipulative experiments to test if adding conspecific cues (i.e., vocalizations and decoys) to newly-built structures affected prospecting visits by Barn Swallows (1) during pre-breeding, (2) during post-breeding, and (3) during or after broadcasts of vocalizations compared to before broadcasts. Additionally, we monitored nesting following pre- and post-breeding cues. We built one nesting structure with and one without conspecific cues at each of 10 study sites in southern Ontario, Canada where nesting habitat was recently lost. We detected about twice as many Barn Swallows immediately after conspecific broadcasts compared to before. We did not find substantial differences in abundance and interactions with new nesting structures for other comparisons involving conspecific cues. Following pre-breeding cues at 10 sites, six nests were built in three of 10 structures treated with conspecific cues, compared to five nests in four of 10 structures without cues. In the subsequent breeding season following post-breeding cues at eight sites, four nests were built in two of eight structures treated with conspecific cues, compared to four nests in three of eight structures without cues. Conspecific vocalizations appeared to increase prospecting behaviour, but not the number of nests, at new nesting structures. The paucity of nests on new structures suggests that building shed-like structures may not be an effective method of mitigating loss of nesting habitat.
\end{abstract}

Key words: Aerial insectivore; conspecific attraction; habitat restoration; nesting habitat; Ontario; prospecting; public information; social cues

\section{Introduction}

Social cues provide inadvertent information from an animal engaged in its activities and convey information about a species' habitat that can be observed by other animals (Danchin et al. 2004). There is empirical evidence that territorial and colonial-nesting migratory birds can be attracted to nesting areas by experiments that introduce conspecific cues (e.g., Ahlering and Faaborg 2006; Hahn and Silverman 2006; Farrell et al. 2012). Thus, conspecific cues have potential application in conservation of various species to attract nesting birds to restored or protected habitat.

Previous research has shown that migratory songbirds can be attracted with conspecific cues to locations that do not provide typical conditions of a species' breeding habitat (Nocera et al. 2006). Such circumstances could produce an ecological trap, in which individuals identify a location as breeding habitat because of artificial conspecific cues, but the location negatively affects breeding (Schlaepfer et al.
2002). Alternatively, if conspecific cues increase the size of a breeding colony, there may be increases in reproductive success through various mechanisms such as predator dilution, group vigilance, or extra-pair paternity (Parrish and Edelstein-Keshet 1999; Danchin et al. 2000). Prospecting behaviour to visit potential nesting areas can occur before, during, or after the breeding season for adults and late in the breeding season for hatch-year birds, after they are independent from parents (Reed et al. 1999; Doligez et al. 2004; Ward 2005).

Conspecific cues could potentially aid conservation of Barn Swallow (Hirundo rustica erythrogaster), an aerial insectivore. Populations of birds that forage on flying insects while in flight have declined markedly over the last several decades in North America (Nebel et al. 2010; Sauer et al. 2013, 2017; Smith et al. 2015), leading to conservation concern and recovery efforts. These aerial insectivores include species from four taxonomic families: 
nighthawks and nightjars (Caprimulgidae), swifts (Apodidae), tyrant flycatchers (Tyrannidae), and swallows (Hirundinidae). Barn Swallow is the most abundant and widespread swallow species worldwide (Brown and Brown 1999) and considered least concern by the International Union for Conservation of Nature (BirdLife International 2016). Although still common in many rural areas, the Barn Swallow population declined by $80 \%$ in Canada and $66 \%$ in Ontario between 1970 and 2012 (Heagy et al. 2014), leading to its listing as threatened by the governments of Canada (Government of Canada 2017) and Ontario (MECP 2012). The reasons for its population decline are not well understood, but potential causes include: (1) loss of nesting habitat; (2) loss or degradation of foraging habitat impacting prey insects; (3) climate change and mortality from extreme cold weather events on breeding grounds; (4) pollution and pesticides; (5) reduced fecundity because of predation, ectoparasites, and persecution by humans; and (6) loss of, and human disturbance at, roosts (COSEWIC 2011; Heagy et al. 2014).

In Ontario, Barn Swallows breed predominantly south of the Canadian Shield in the Mixedwood Plains ecozone (Lepage 2007). They breed in various non-forested areas and are typically associated with human-built structures that provide nesting opportunities, such as barns, bridges, and sheds (Brown and Brown 1999). Recently, structures specifically designed as Barn Swallow nesting habitat have been built. In Ontario, most nesting structures are built as mitigation for habitat loss as required by the Ontario Ministry of Environment, Conservation and Parks (e.g., due to building or bridge demolition or renovation; MECP 2013); others are built to provide new nesting habitat. There are reports providing information about nesting in these structures (e.g., Heagy et al. 2014; K.R. unpubl. data), but we were unable to find information in the literature. Overall, the frequency of use of these structures for nesting by Barn Swallows is unclear because few results are available. Although loss of nesting habitat is only one potential factor contributing to Barn Swallow population declines, it is important for conservation efforts that address habitat loss to make the best use of funds and opportunities by providing nesting habitat that is most likely to be used productively by the species.

Barn Swallows often nest colonially (Brown and Brown 1999), suggesting they may use conspecific cues (e.g., the presence of adults at a nesting structure) when selecting nest sites. There is some evidence of success in using conspecific cues to attract Purple Martin (Progne subis; another swallow species) to nest in previously unoccupied martin houses (Kostka 2000). We hypothesized that introducing conspecific cues (i.e., decoys and vocalizations), to make it appear that a structure was already being used by nesting Barn Swallows, would increase the likelihood of nesting at a new structure.

There is evidence that the presence of old nests influences the use of a nest site by Barn Swallows. Safran (2004) found that removing old nests before birds arrived on the breeding grounds reduced the proportion of immigrant female Barn Swallows at sites in New York. Additionally, birds that reused old nests had higher seasonal fecundity than those that built new nests (Safran 2004). Settlement patterns of females breeding at a site for the first time were associated with the number of old nests, rather than the prevalence of colourful males or opportunities for extra-pair copulations (Safran 2007). Ringhofer and Hasegawa (2014) found that the number of old undamaged nests was associated with the spring arrival date of male Barn Swallows at nest sites. Thus, both conspecific cues and the presence of old nests likely influence the use of nest sites by Barn Swallows.

Barn Swallows likely gather information about numerous potential nest sites before selecting one for breeding, as occurs with other migratory songbirds (Brown and Brown 1999; Reed et al. 1999). Visits to nesting structures by Barn Swallows likely indicate that individuals are gathering information about the structure for potential future use for nesting. Attracting Barn Swallows to new nesting structures could positively or negatively influence reproductive success. Breeding success of Barn Swallows can decrease with increasing number of proximate nests (Shields and Crook 1987); however, it is unknown how the use of conspecific cues might influence the reproductive success of the species.

Our goal was to test the influence of conspecific cues on the use of newly built nesting structures by Barn Swallows to inform conservation efforts that include the creation of nesting structures. In experiment one, we monitored pre-breeding prospecting visits by Barn Swallows to assess if birds visited structures with conspecific cues (i.e., vocalizations and decoys) more frequently than structures without cues. In experiment two, we monitored post-breeding prospecting visits to assess if birds visited structures with conspecific cues more frequently than structures without cues. In experiment three, we further investigated the immediate response to conspecific vocalizations by assessing if Barn Swallows visited structures more frequently during or after vocalization broadcasts compared to before broadcasts. Additionally, we monitored nesting following preand post-breeding cues to assess if conspecific cues influenced the number and success of Barn Swallow nests at nesting structures. 


\section{Study Area}

We located study sites where an old structure with nesting Barn Swallows was removed or made unavailable to the birds. This situation enabled us to simulate the circumstances under which many new nesting structures are being built in Ontario (i.e., mitigation for loss of nesting habitat under the Endangered Species Act [MECP 2013]). We coordinated the construction of two new nesting structures at each site, during the fall or spring, prior to the breeding season. The result was a paired design, with two new nesting structures on each study site, one treatment with conspecific cues and one control without conspecific cues, thus allowing us to assess the influence of the cues on Barn Swallow use of the new nesting structures. We flipped a coin to randomly select one of the two structures on each of the 10 study sites to have conspecific cues (i.e., decoys and a broadcast box).

We established 10 study sites in southern Ontario between Erin $\left(43.766^{\circ} \mathrm{N}, 80.058^{\circ} \mathrm{W}\right)$ in the north and Port Rowan $\left(42.626^{\circ} \mathrm{N}, 80.452^{\circ} \mathrm{W}\right)$ in the south. We opportunistically identified study sites through existing contacts and by directly contacting landowners. Barn Swallow nesting habitat was lost at study sites prior to our study because structures were demolished or access to structures was blocked due to building renovation, nesting deterrents, or a need to keep doors closed (Table 1). The number of Barn Swallow nests in structures where habitat was lost varied, from one to $\sim 50$, across study sites (Table 1). We were unable to estimate the number of nests that were used in the year before habitat was lost, which would have provided better information about the number of nesting pairs compared to the number of nests. To the best of our knowledge, Barn Swallows nested at $\geq 8$ of the 10 study sites in the year prior to our experiment.

We used the following criteria to guide where to place new nesting structures. We placed structures in non-forested areas with foraging habitat for Barn Swallows (i.e., grassland, cropland; Brown and Brown 1999). Additionally, we attempted to build new structures $\leq 1 \mathrm{~km}$ from the previous nesting location to meet mitigation guidelines (MECP 2013) and so that Barn Swallows returning to the site could easily encounter the new structures. We attempted to place the two new structures equal distances from the location of the demolished, renovated, or closed structure and about $400 \mathrm{~m}$ apart from each other to minimize the effects of the conspecific cues on the control structure (i.e., to ensure that broadcasted vocalizations were inaudible at control structures). Additionally, we attempted to place structures $>100 \mathrm{~m}$ from forest edges to maximize availability of proximate foraging habitat. Because of constraints on study sites, we placed nesting structures $81-1220 \mathrm{~m}($ mean $=427 \mathrm{~m})$ from the location where Barn Swallows nested previously, 265-589 $\mathrm{m}($ mean $=378 \mathrm{~m})$ apart from each other, and $16-474 \mathrm{~m}($ mean $=167 \mathrm{~m})$ from the nearest forest edge based on land cover data from the Southern Ontario Land Resource Information System (MNRF 2000).

\section{Methods}

\section{Structures}

We designed nesting structures using the best available information about what Barn Swallows would most likely use (Brown and Brown 1999). However, information about structures built for Barn Swallow nesting is limited and not in the literature. The best available information suggested building

TABLE 1. Reason for habitat loss, number of Barn Swallow (Hirundo rustica erythrogaster) nests in lost habitat in year before monitoring (number of previously-active nests unknown), number of new nests in structures with and without prebreeding conspecific cues built to replace lost habitat, and the year each study site was monitored.

\begin{tabular}{|c|c|c|c|c|c|}
\hline \multirow{2}{*}{ Site } & \multicolumn{2}{|c|}{ Old structure } & \multicolumn{2}{|c|}{ No. nests in new structure } & \multirow{2}{*}{$\begin{array}{c}\text { Year } \\
\text { monitored }\end{array}$} \\
\hline & Habitat lost & No. nests & Conspecific cues & No cues & \\
\hline $\mathrm{AN}$ & Barn demolished & $\sim 12$ & 2 & 2 & 2014 \\
\hline $\mathrm{CH}$ & Barn access denied & Unknown* & 0 & 0 & 2015 \\
\hline DA & Barn access denied & 1 to $2 \dagger$ & 0 & 0 & 2015 \\
\hline DR & Barn access denied & $\sim 6$ pairs + & 0 & 0 & 2015 \\
\hline GU & Barn access denied & $1 \S$ & 0 & 0 & 2015 \\
\hline LA & Barn demolished & 6 & 0 & 1 & 2014 \\
\hline LE & Barn demolished & 20 to 50 & 2 & 1 & 2015 \\
\hline RA & Eaves access denied & 1 & 2 & 0 & 2015 \\
\hline WA & Barn access denied & 4 to 5 & 0 & 1 & 2015 \\
\hline WI & 3 buildings demolished & $\sim 15$ & 0 & 0 & 2015 \\
\hline
\end{tabular}

*Landowner observed several nesting pairs previously using structure, but structure was inaccessible to confirm presence of nests.

$\dagger$ Nests active in 2012.

†Number of nests unknown, landowner estimated six nesting pairs.

§Unknown if nest active in 2014. 
structures with similar characteristics to bridges and barns that are used for nesting, including rough vertical surfaces on which birds can build nests, shelter from wind and rain, visual barriers between nests, and a structure large enough to support several nesting pairs (MECP 2013; L. Sarris pers. comm. 13 February 2014; K.R. unpubl. data). We designed a wooden structure with a metal roof, $4.9 \mathrm{~m}$ long, 1.3 $\mathrm{m}$ wide at the nesting compartments, and $3.7 \mathrm{~m}$ tall at the peak of the roof (Figure 1). The structure included 16 nesting compartments, two rows of eight compartments along the 4.9-m length of the structure. In each row of eight compartments, we alternated available nest supports by providing a wooden nest cup (i.e., a wooden replica of a nest) in one compartment and bridging in the shape of the letter $\mathrm{X}$, as found in some old barns, in the next compartment. Each compartment was bordered by $5 \times 25 \mathrm{~cm}$ lumber along the center and along the outside of the structure and $5 \times$ $15 \mathrm{~cm}$ lumber between compartments on the inside of the structure to provide a visual barrier between nests. Compartments had a flat ceiling above and no obstructions below. To provide shelter from weather, we added $40 \mathrm{~cm}$ of lumber along the outside of the structure below the nesting compartments.

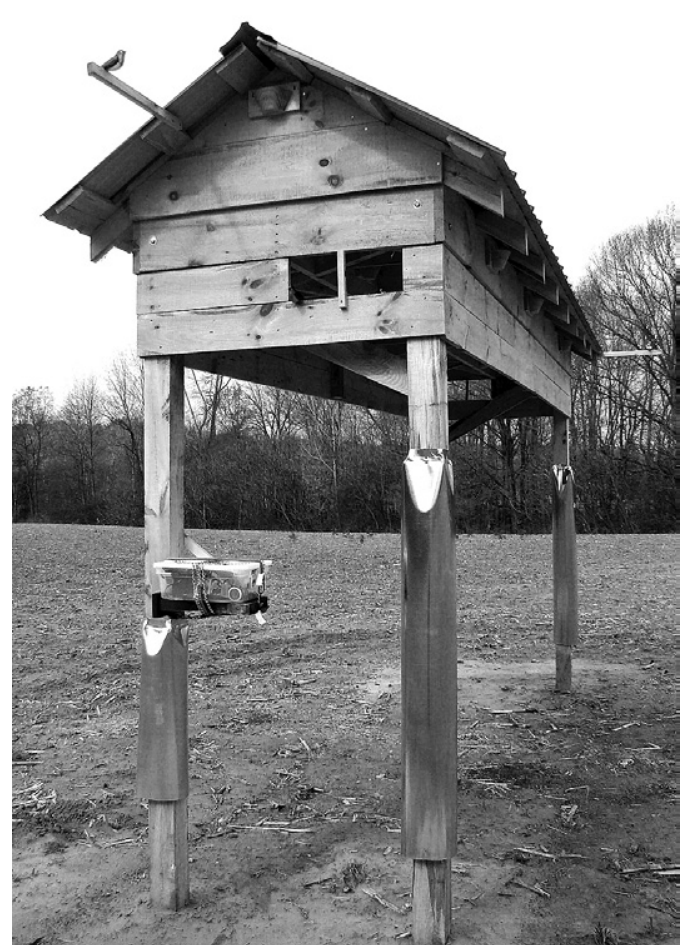

Figure 1. One of the nesting structures built to test the impact of conspecific cues on prospecting and nesting by Barn Swallows (Hirundo rustica erythrogaster) in southern Ontario, Canada. Photo: A.J. Campomizzi.
Each structure was equipped with nest cups, perches, and predator deterrents to encourage use by Barn Swallows and decrease risk of nest predation. We placed nest cups on all structures because they are required for mitigation projects in Ontario (MECP 2013). Although the presence of old nests may increase the chance of nesting, Barn Swallow response to nest cups is unknown. We placed 16 nest cups on each structure, eight on the inside and eight on the outside of the structure. We placed nest cups far enough from ceilings $(6.4 \mathrm{~cm})$ and roofs $(6.4 \mathrm{~cm}$ under roof peaks and $10.8 \mathrm{~cm}$ under sloped roofs) to allow the birds to build a mud rim along the top of the cup. The distance between the top of the nest cup and the ceiling or roof above was based on instructions provided by a nest cup supplier (American Artifacts, Taneytown, USA) and Barn Swallow nest placement (i.e., typically 2.5 to $6.0 \mathrm{~cm}$ from a ceiling; Brown and Brown 1999). We attached four perches to each structure; two on the inside and two on the outside. We included perches on the structures because there is evidence that adults lead juveniles from the nest to a perch, fledglings frequently perch after leaving the nest, and fledglings are initially fed by parents while perched (Brown and Brown 1999). To deter mammalian nest predators from accessing and preying on nests, we covered each support post with galvanized sheet metal (Figure 1).

\section{Experiment one: pre-breeding prospecting}

We monitored structures at 10 study sites (two sites in 2014 and eight in 2015). We placed seven carved Barn Swallow decoys (Olde World Carvings, Spartanburg, South Carolinia, USA; Starr Decoys, Weybridge, Vermont, USA) at each treatment structure on perches and nests to make it appear as though the structure was being used, but not fully occupied, by nesting Barn Swallows.

We attached the broadcast box to a small shelf about $1.5 \mathrm{~m}$ from the ground on a post that supported each treatment structure. We largely followed Farrell and Campomizzi (2011) for the design of the broadcast box, resulting in a plastic box containing a compact disc player, amplified speaker, battery, and timer that broadcasted Barn Swallow vocalizations periodically throughout the day. We made a 30-min audio track of Barn Swallow songs, non-alarm calls, and periods of silence to simulate an active Barn Swallow nesting colony. To assemble the 30-min track, we obtained eight audio recordings made in Ontario and adjacent US states from the Cornell Lab of Ornithology (2014). To provide vocalizations throughout the day, we programmed the timer to turn the broadcast box on for $30 \mathrm{~min}$ at 0600, 0700, 0800, 1000, 1200, 1500, 1700, and 1900. We used the literature about Barn Swallow vocalizations to guide our selection of songs 
and calls to include, when to broadcast the vocalizations during the day, and the number of vocalizations interspersed with silence (Samuel 1971; Brown 1985; Brown and Brown 1999). We installed conspecific cues for the return of Barn Swallows to the study area for breeding in the spring. We continued broadcasting vocalizations for the duration of the nesting season, until late August in 2014 and early September in 2015.

Across 2014 and 2015, we monitored 10 treatment and 10 control structures for pre-breeding prospecting visits by Barn Swallows to assess if birds visited structures with conspecific cues more frequently than structures without cues and to record their behaviour. We conducted prospecting surveys at a designated survey location $50 \mathrm{~m}$ from each structure twice per week, between sunrise and sunset. Pre-breeding prospecting surveys occurred from 24 April to 14 June. This period corresponds to Barn Swallow arrival in the study area and the beginning of nesting. Seven to 21 days pass between pair formation and egg laying (Brown and Brown 1999) and the earliest egg date for Ontario is 10 May (Peck and James 1987).

During each 10-min survey, we recorded each Barn Swallow detected within 50 horizontal $\mathrm{m}$ of the structure. During each 2-min interval of the 10-min survey, we recorded each individual detected, its distance from the structure, if it behaviourally interacted with the structure (perched on, flew under, or flew into or out of the structure). We also recorded if we detected an individual carrying nest material during the 10 -min survey and if birds interacted with, perched next to, or attempted to copulate with decoys. We recorded a conservative estimate of the number of individuals to avoid counting one individual multiple times during a survey. We conducted surveys during weather conducive to Barn Swallow activity and detection (i.e., not during rain or strong wind). We noted if nest predators were on or attempting to get on the structure. After each survey, we walked to the structure to see if birds were inside and to monitor nests, as described below.

\section{Experiment two: post-breeding prospecting}

Following the pre-breeding prospecting experiment at each study site, we monitored 10 treatment and 10 control structures for post-breeding prospecting visits by Barn Swallows to assess if birds visited structures with conspecific cues more frequently than structures without cues, and to record their behaviour. Using the same broadcast schedule of Barn Swallow vocalizations and bird survey methods described above, we conducted post-breeding surveys from 20 July to 5 September, a range that includes when pairs not attempting second broods are finishing caring for dependent fledglings to when we no longer saw birds in breeding areas. The latest egg date for Ontario is 21 August (Peck and James 1987).

\section{Experiment three: prospecting before, during, and after}

In 2016, we placed conspecific vocal cues at three structures that were randomly selected as treatments in 2015 but were not used for nesting by Barn Swallows in 2015. In 2016, each of the three study sites had a pair of structures, one with and one without conspecific vocal cues. We did not use decoys for experiment three.

We changed the frequency and duration of vocalizations played on each day at each treatment structure compared to 2015 to enable assessment of Barn Swallow visits before, during, and after broadcasts of vocalizations. Vocalizations played for $20 \mathrm{~min}$ at the start of each hour between 0600 and 2100. Broadcasts began on 19 April and ceased on 6 June.

In 2016, we surveyed the three nesting structures for pre-breeding prospecting visits by Barn Swallows. We designed surveys to document Barn Swallows searching for nest sites (particularly behavioural interactions with structures) and if conspecific cues influenced the frequency of detections. We visited treatment structures twice per week, once in the morning and once in the afternoon or evening, for a one hour survey. We scheduled the majority of surveys during the morning and evening because, in 2014 and 2015, we observed more Barn Swallow activity during these times compared to other times. The survey hour consisted of $20 \mathrm{~min}$ before the broadcast, $20 \mathrm{~min}$ of broadcast, and 20 min after the broadcast. We observed treatment structures from a designated survey location $50 \mathrm{~m}$ away, recording all individual Barn Swallows that came within 50 horizontal m. Survey periods were broken into 5-min intervals to record possible variation in bird abundance and behaviour throughout the survey. During each 5-min interval, we recorded detections of each individual. For each Barn Swallow detected, we recorded its horizontal distance from, and interactions with, the nesting structure. We conducted surveys during weather conducive to Barn Swallow activity and detection.

After each survey, we approached the treatment structure to look for signs of nesting and check active nests. We did not conduct prospecting surveys of the control structures on the three study sites because we were testing Barn Swallow response to broadcasts at treatment structures only (prospecting surveys at control structures were conducted for the prebreeding and post-breeding prospecting experiments, see above). We checked for nesting activity at control structures after surveys were completed at treatment structures.

\section{Nest monitoring}

We monitored nests to assess differences in the number of nests and nest success of Barn Swallows 
between structures with and without conspecific cues. We monitored 10 study sites across 2014 and 2015 following pre-breeding conspecific cues. Additionally, we monitored nesting at eight study sites in 2016 following post-breeding conspecific cues applied in 2015. Nest monitoring occurred from 12 May to 22 August. We followed nest monitoring protocols for Barn Swallows provided on Bird Studies Canada's Project NestWatch website (http://www.birdscanada. org/volunteer/pnw/index.jsp?targetpg=barsmonitor), with minor modifications. We looked for evidence of nest building while conducting bird surveys early in the breeding season. At the five study sites without bird surveys in 2016, the frequency of nest monitoring visits varied based on whether there were active nests at the site. We checked active nests approximately once per week until nesting activity ceased. Sites without active nests were checked periodically throughout the season.

We began monitoring nests with a mirror to observe nest contents on the visit after a nest appeared fully built, to minimize the chance of nest abandonment. We checked nest contents with a mirror once every five to seven days. During each nest check, we recorded the number of eggs, number and age of young, brood parasitism, adult activity, and condition of the nest. We did not check nest contents with a mirror if nestlings were $>10$ days old, to avoid potentially causing young to fledge prematurely; instead, we observed the nest from a distance with binoculars. We continued to check nesting structures for active nests throughout the breeding season.

\section{Analyses}

We did not use statistical analyses for nest data because sample size of nests was too small. Instead, we described nesting activity. For bird survey data, we first explored data through graphs and descriptive statistics. We excluded survey data collected while Barn Swallow nests were active at a structure to ensure that detections were of prospecting birds, not adults attending to nests. We used means and CI to assess the direction, magnitude, and precision of effects (Johnson 1999; Wasserstein and Lazar 2016), and interpreted their biological importance (Guthery et al. 2001; Nakagawa and Cuthill 2007; Nuzzo 2014). We calculated means and CI for the difference in Barn Swallow detections and interactions with structures from spatially and temporally paired surveys described below. We conducted analyses using $\mathrm{R}$ (version 3.4.1, R Core Team 2017).

Experiment one: pre-breeding prospecting: We separately compared the abundance of Barn Swallows detected and interacting with structures during prebreeding surveys. We compared the difference in abundance of Barn Swallows detected between (1) broadcast and non-broadcast times at treatments, (2) broadcast and non-broadcast times at controls, and (3) all surveys at treatments compared to controls. We made the same three comparisons in the difference in the abundance of Barn Swallows interacting with structures. For comparisons during broadcast and non-broadcast times at treatments and controls, we paired surveys conducted during the same week for each structure. For example, to calculate the difference in abundance between broadcast and nonbroadcast times at each treatment structure for each week of surveys, we subtracted the number of Barn Swallows detected during the non-broadcast time from the number of individuals detected while conspecific vocalizations were broadcasted. For comparisons between treatments and controls, we paired surveys conducted on the same day for each pair of treatment and control structures at each study site. These analyses resulted in three estimates of the difference in abundance of Barn Swallows detected at structures (Figure 2a) and another three estimates of the difference in abundance of individuals interacting with structures (Figure 2b) during pre-breeding surveys. Estimated means greater than zero indicate more Barn Swallows detected or interacting with structures during broadcast compared to non-broadcast or treatment compared to control.

Experiment two: post-breeding prospecting: For post-breeding surveys, we made the same comparisons as pre-breeding surveys with one exception. We used surveys at treatments during broadcast and controls during non-broadcast only because mean abundance at treatments was more than twice as high during broadcast compared to non-broadcast times, suggesting a potential numerical response by the birds. These analyses resulted in an additional three estimates of the difference in abundance of Barn Swallows detected at structures (Figure 2a) and three estimates of the difference in abundance of individuals interacting with structures (Figure 2b) during post-breeding surveys.

Experiment three: prospecting before, during, and after: We compared the difference in abundance of Barn Swallows detected at treatment structures during broadcast versus before broadcast and after broadcast versus before. We paired data for surveys conducted on the same day for each structure. We were unable to make comparisons of the abundance of Barn Swallows interacting with structures because we did not detect interactions during these surveys. These analyses resulted in two estimates of the difference in abundance of Barn Swallows detected at structures (Figure 3). Estimated means greater than zero indicate more Barn Swallows detected during broadcast compared to before broadcast or after broadcast compared to before. 

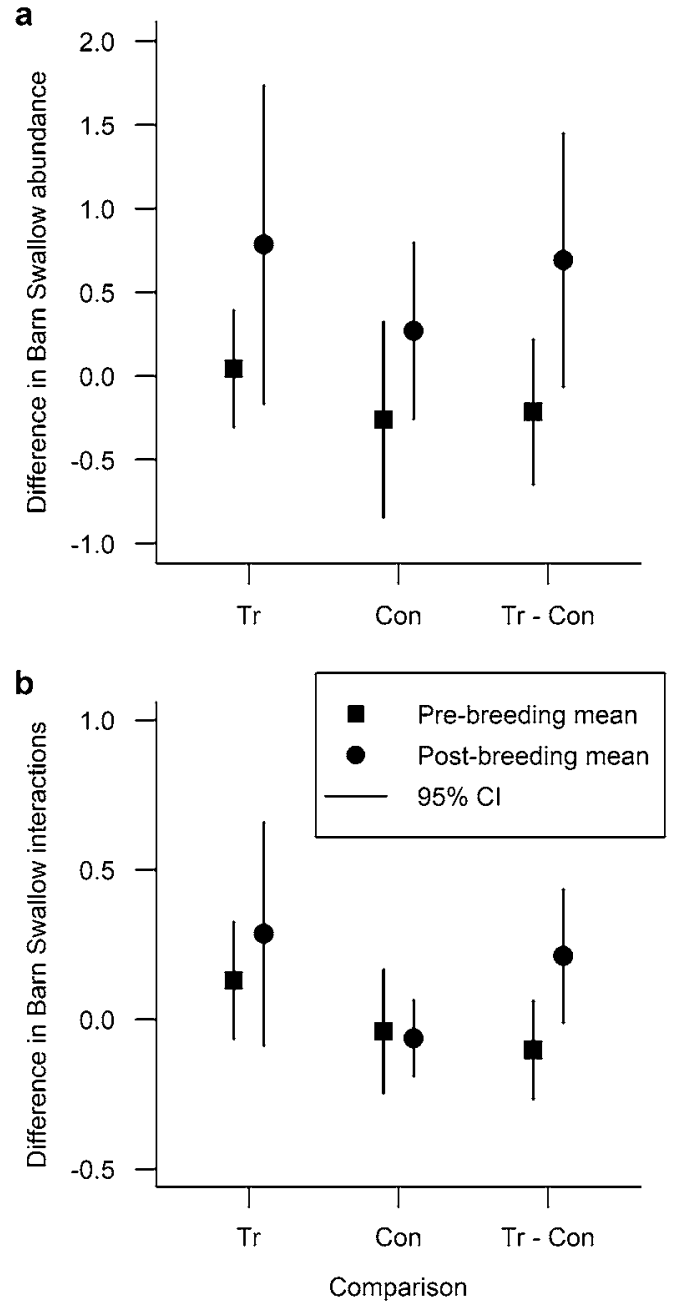

Figure 2. Mean and $95 \% \mathrm{CI}$ of the difference in abundance of Barn Swallows (Hirundo rustica erythrogaster) a. detected and $b$. interacting with nesting structures (i.e., perched on, flew under, or flew into or out of the structure) with and without conspecific cues in southern Ontario, Canada in 2014 and 2015. Comparisons during pre-breeding are for structures treated with conspecific cues during broadcast minus non-broadcast surveys (Tr), control structures during broadcast minus non-broadcast surveys (Con), and all treatment minus control surveys ( $\mathrm{Tr}$ - Con). Comparisons during post-breeding are the same for $\operatorname{Tr}$ and Con; the third comparison is of treatment during broadcast minus control during non-broadcast surveys only ( $\mathrm{Tr}$ - Con).

\section{Results}

Across all surveys in 2014 and 2015, we detected Barn Swallows on 33\% $(n=263)$ of surveys at structures with conspecific cues and $38 \%(n=$ 263 ) of surveys at structures without cues. Across

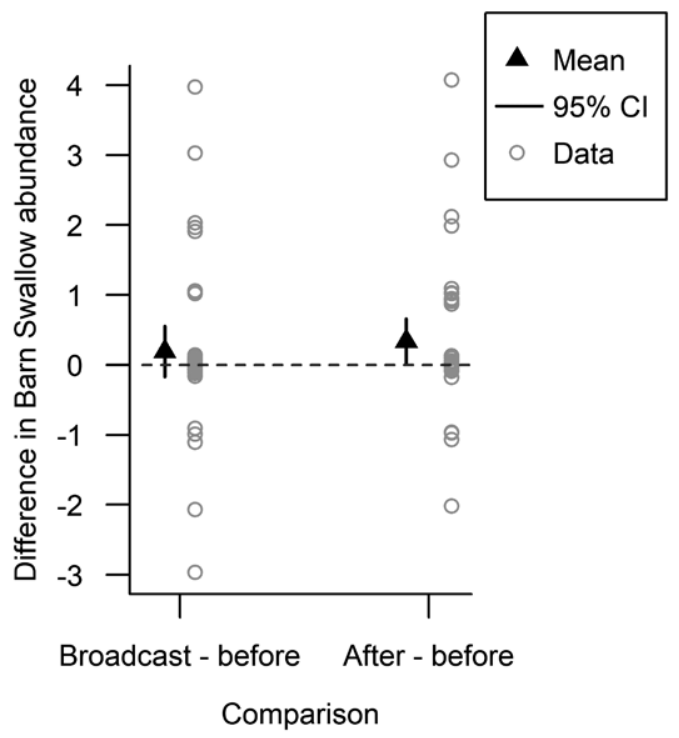

Figure 3. Mean, $95 \% \mathrm{CI}$, and observed data of the difference in abundance of Barn Swallows (Hirundo rustica erythrogaster) detected on one hour surveys conducted for 20 min before, during, and after conspecific vocalizations at three nesting structures in southern Ontario, Canada in 2016.

surveys with Barn Swallow detections, we detected 279 Barn Swallows on 88 surveys at structures with conspecific cues and 299 Barn Swallows on 99 surveys at structures without cues. These results include data from surveys of structures with active nests. As noted above, we reduced the dataset for the comparisons below.

\section{Experiment one: pre-breeding prospecting}

During pre-breeding, the mean difference in Barn Swallow abundance during broadcast compared to non-broadcast times at treatments was $0.04(n=46)$ and not substantially different from zero (Figure 2a). Similarly, the mean difference in Barn Swallow abundance during broadcast compared to non-broadcast times at controls $(-0.26, n=50)$ and at treatments compared to controls $(-0.21, n=98)$ was not substantially different from zero (Figure $2 \mathrm{a}$ ).

\section{Experiment two: post-breeding prospecting}

During post-breeding, all three mean differences in Barn Swallow abundance were larger than during pre-breeding and greater than zero. The mean difference in Barn Swallow abundance during broadcast compared to non-broadcast times was $0.78(n=42)$ at treatments, $0.27(n=48)$ at controls, and $0.69(n=$ $52)$ at treatments compared to controls. These differences suggest an effect of $\sim 0.5$ individuals per survey, but $95 \%$ CI included zero, although marginally for treatments compared to controls (lower 95\% CI: -0.06 ; Figure 2a). 
The largest differences in abundance of Barn Swallows interacting with structures was during postbreeding. The mean difference in Barn Swallows interacting with structures during broadcast compared to non-broadcast was $0.28(n=42)$ at treatments and $0.21(n=52)$ for treatments compared to controls (Figure 2b). Both CI marginally included zero (lower 95\% CI: -0.09 for treatments and -0.01 for treatments compared to controls), indicating some lack of confidence in an effect of $\sim 0.2$ individuals per survey interacting with structures (Figure 2b).

Experiment three: prospecting before, during, and after

We detected 40 individual Barn Swallows on prospecting surveys in 2016 and $45 \%(n=42)$ of surveys for this experiment had Barn Swallow detections. We detected 12, 20, and 26 individuals before, during, and after conspecific broadcast, respectively. Mean difference in abundance of Barn Swallows detected at treatment structures was higher both during broadcast compared to before broadcast $(0.19, n=42)$ and after broadcast compared to before $(0.33, n=42$; Figure 3). The CI for after broadcast compared to before was greater than zero (95\% CI: 0.01, 0.65; Figure 3). We did not observe Barn Swallows behaviourally interacting with structures (i.e., perching on or flying inside of a structure) in 2016.

\section{Nesting}

Experiment one: pre-breeding prospecting: Across 2014 and 2015, there were six nests on three structures with conspecific cues and five nests on four structures without cues (Table 1). All nests observed with eggs eventually fledged young. Two additional nests were built on structures without cues; however, we never observed eggs in these nests. All three nesting pairs at structures with conspecific cues appeared to fledge a second clutch, compared to one of four pairs nesting at structures without cues. The earliest nest initiation date (i.e., first egg date) was 20 May at structures with conspecific cues and 21 May at structures without cues.

All nests were built in wooden nest cups in the interior of the structures. For all 11 nests monitored following pre-breeding cues, Barn Swallows added a mud rim to the top of the wooden nest cup, making the top of the nest look similar to a typical Barn Swallow nest.

Experiment 2: post-breeding prospecting: In 2016, four nests were built in two of eight structures treated with post-breeding conspecific cues in 2015, compared to four nests in three of eight structures without post-breeding cues in 2015. All eight nests were in nest cups in the interior of the structure and fledged young. One additional nest was initiated on the ex- terior of a structure but was abandoned after some addition of mud to a nest cup; we did not observe eggs in this nest. Two nests from 2015 were reused in 2016. Three of the eight nests appeared to be second clutches.

Experiment 3: prospecting before, during, and after: Barn Swallows did not nest at the three sites used for the experiment comparing prospecting before, during, and after broadcasts of vocalizations in 2016.

\section{Discussion}

To our knowledge, this is the first evaluation of Barn Swallow use of new nesting structures specifically built for the species. Our study provides some evidence to link prospecting behaviour by Barn Swallows at new nesting structures to broadcasts of conspecific vocalizations. During pre-breeding, Barn Swallow abundance was higher immediately after conspecific broadcasts compared to before broadcasts. However, we did not find substantial differences in Barn Swallow abundance and interactions with new nesting structures for other comparisons involving conspecific cues. Most importantly, Barn Swallows did not nest more frequently on structures treated with pre- or post-breeding conspecific cues; they nested on and fledged young from structures with and without cues, albeit in low numbers.

Our results provide some evidence that Barn Swallows can be attracted to at least investigate new nesting structures by introducing conspecific cues. On several occasions, we observed Barn Swallows approaching nesting structures immediately after the broadcast started, anecdotally suggesting a response to the start of the vocalizations. On a few occasions, we observed Barn Swallows interacting with decoys by perching on, singing at, and attempting to copulate with decoys. Previous research in the literature has not documented Barn Swallow prospecting behaviour in response to simulated conspecific cues at nesting sites. A study on Chimney Swift (Chaetura pelagica; another aerial insectivore species) showed that introducing conspecific vocalizations and decoys increased the length of time that the birds spent near new nesting towers (Finity and Nocera 2012). Additionally, conspecific cues introduced during post-breeding have been shown to influence habitat selection in the next breeding season for migratory songbirds (Nocera et al. 2006, Betts et al. 2008). In our study, however, Barn Swallows did not build more nests in 2016 at structures treated with conspecific cues during post-breeding in 2015, compared to structures without cues. Future research to explore the impacts of broadcasted conspecific vocalizations on prospecting behaviour and nesting may help in- 
form future efforts to create nesting habitat for various species.

Some of the structures included in this project provided nesting habitat for Barn Swallows and all nests observed with eggs fledged young. We did not observe a difference in the number of nests built on structures with and without conspecific cues that were provided during pre-breeding or post-breeding. Although nesting structures provided opportunities for birds to nest on X-shaped bridging in addition to nest cups, all nests were built in nest cups. Nest cups may be an important feature of new nesting structures because they provide a nesting substrate and essentially a partially-built nest. The nest cups may attract Barn Swallows to new structures if they function similarly to old nests (sensu Safran 2004, 2007; Ringhofer and Hasegawa 2014) and enable birds to begin nesting earlier in the season because the birds do not need to build an entire nest. Re-using old nests can increase reproductive success (Safran 2007; but see Barclay 1988). Therefore, nest cups could be important for conservation because they may enable Barn Swallow pairs to raise a second brood, thus increasing fecundity. Combining conspecific cues and the presence of old nests (perhaps by providing wooden nest cups) may maximize the number of Barn Swallows that prospect at new nesting structures but may not lead to more nests at new structures.

It is possible that the structures with and without cues were not far enough apart to completely separate the effect of the conspecific cues. Although the distance Barn Swallows travel to prospect for nest sites is unknown, adults will forage up to $500 \mathrm{~m}$ from nesting colonies (Møller 1987), suggesting individuals encountering one structure on a study site could encounter the other structure. Future research to assess if conspecific cues at one structure can affect prospecting at multiple structures, or if prospecting is greater at structures with conspecific cues compared to structures without cues (at greater distances than we tested), may be helpful for understanding nest site selection and guiding conservation efforts. Additionally, most of our study sites had few nests in the nesting habitat that was lost. With few Barn Swallows returning to nest at these sites, there may have been few Barn Swallows within hearing distance of the vocalizations. The number of philopatric Barn Swallows may impact the magnitude of the effect of conspecific cues on prospecting birds.

We are uncertain how many nesting pairs could nest simultaneously on the structures used for our experiment. However, building a few of these new structures is unlikely to replace the lost nesting habitat provided by bridges or old barns with large nesting colonies (e.g., 50 breeding pairs). Building one nesting structure cost $\sim \$ 2500$ to $\$ 3500$ (CAD). Regulators and land managers should consider if this expense is worth the benefit or if funds could be used in more effective ways to support Barn Swallow nesting habitat. A potential alternative is to provide incentives for landowners to repair and maintain aging barns that can provide nesting habitat for larger colonies of Barn Swallows and for more years than new structures (Heagy et al. 2014). It may also be beneficial for future research to investigate the relationship between colony size and characteristics of nesting structures and the surrounding landscape. Building new nesting structures may be an option for creating new Barn Swallow nesting habitat in locations with appropriate foraging habitat (i.e., grassland, cropland; Brown and Brown 1999), where no structure currently exists and there is an interest in contributing to Barn Swallow conservation. When structures are built for Barn Swallow nesting habitat, we recommend including wooden nest cups in the interior of the structure, which was the location of all nests in our experiment. However, more research is needed to assess if loss of nesting habitat is limiting the Barn Swallow population to determine if creating or maintaining nesting habitat is likely to have a positive impact on the population or if resources should be directed to addressing other threats to the species.

Our results confirm that new structures can provide nesting habitat for Barn Swallows but providing conspecific cues may not enhance this conservation strategy. The paucity of nests built on structures raises questions about the efficacy and efficiency of building new nesting structures to mitigate the loss of nesting habitat.

\section{Author Contributions}

Conceptualization: Z.M.L., A.J.C., and K.R.; Data Curation: A.J.C. and Z.M.L.; Formal Analysis: A.J.C.; Funding Acquisition: K.R., Z.M.L., and A.J.C.; Investigation: Z.M.L., A.J.C., and K.R.; Methodology: A.J.C., Z.M.L., and K.R.; Project Administration: Z.M.L., K.R., and A.J.C.; Resources: Z.M.L. and K.R.; Supervision: Z.M.L. and K.R.; Validation: A.J.C. and Z.M.L.; Visualization: A.J.C. and Z.M.L.; Writing - Original Draft: A.J.C. and Z.M.L.; Writing - Review \& Editing: A.J.C., Z.M.L., and K.R.

\section{Acknowledgements}

Funding for this project was provided by the Government of Ontario, TD Friends of the Environment Foundation, The City of Waterloo, Colleges and Institutes Canada Clean Tech Internship program, Echo Foundation, the Government of Canada (Canada Summer Jobs Program), Ontario Soil and Crop Improvement Association through the Species 
at Risk Farm Incentive Program (SARFIP), and individual donors. We are grateful for assistance with field monitoring from Betty Chanyi, Timothy Fernandes, Rebecca Howe, Jaelyn Kloepfer, Katherine Robbins, Gail Tako, Bob Wood, Graham Wood, Karen Wood, and Carolyn Zanchetta. Thanks to Becky Stewart, Bird Studies Canada, for the opportunity to undertake this project. We also thank the Nature Conservancy of Canada, rare Charitable Research Reserve, The Arboretum at the University of Guelph, The City of Waterloo, and several private landowners for allowing construction and monitoring of nesting structures on their properties. Richard Van Vleck (American Artifacts) and Larry Sarris (Ontario Ministry of Transportation) provided substantial helpful information about structures for Barn Swallows. Thanks to Jeff Sauder (for assistance designing structures and leading construction) and the other builders. Mike Cadman, Tara Imlay, and two anonymous reviewers provided helpful comments on previous versions of this manuscript. The views expressed herein are those of the authors, not funders or other entities.

\section{Literature Cited}

Ahlering, M.A., and J. Faaborg. 2006. Avian habitat management meets conspecific attraction: if you build it, will they come? Auk 123: 301-312. https://doi. org/10.1642/0004-8038(2006)123[301:ahmmca]2.0.co;2

Barclay, R.M.R. 1988. Variation in the costs, benefits, and frequency of nest reuse by Barn Swallows (Hirundo rustica). Auk 105: 53-60. https://doi.org/10.1093/auk/ 105.1.53

Betts, M.G., A.S. Hadley, N. Rodenhouse, and J.J. Nocera. 2008. Social information trumps vegetation structure in breeding-site selection by a migrant songbird. Proceedings of the Royal Society of London B: Biological Sciences 275: 2257-2263. https://doi.org/10. 1098/rspb.2008.0217

BirdLife International. 2016. Hirundo rustica. The IUCN Red List of Threatened Species 2016: e.T22712252A8 7461332. http://doi.org/10.2305/iucn.uk.2016-3.rlts.t227 12252a87461332.en

Brown, C.R. 1985. Vocalizations of Barn and Cliff Swallows. Southwestern Naturalist 30: 325-333. https://doi. org/10.2307/3671263

Brown, C.R., and M.B. Brown. 1999. Barn Swallow (Hirundo rustica), The Birds of North America Online. Edited by A. Poole. Cornell Lab of Ornithology, Ithaca, New York, USA. Accessed 1 February 2014. https:// birdsna.org/Species-Account/bna/species/barswa/ introduction.

Cornell Lab of Ornithology. 2014. Macaulay Library. Accessed 14 April 2014. https://www.macaulaylibrary. org/.

COSEWIC (Committee on the Status of Endangered Wildlife in Canada). 2011. COSEWIC assessment and status report on the Barn Swallow Hirundo rustica in Canada. COSEWIC, Ottawa, Ontario, Canada.

Danchin, E., L.A. Giraldeau, T.J. Valone, and R.H. Wag- ner. 2004. Public information: from nosy neighbors to cultural evolution. Science 305: 487-491. https://doi. org/10.1126/science.1098254

Danchin, E., R.H. Wagner, J.K. Parrish, and L. Edelstein-Keshet. 2000. Benefits of membership. Science 287: 804-807. https://doi.org/10.1126/science.287. $5454.803 \mathrm{e}$

Doligez, B., T. Pärt, and E. Danchin. 2004. Prospecting in the collared flycatcher: gathering public information for future breeding habitat selection? Animal Behaviour 67: 457-466. https://doi.org/10.1016/j.anbehav.2003.03.010

Farrell, S.L., and A.J. Campomizzi. 2011. A component system for broadcasting sound for research and management. Journal of Wildlife Management 75: 463-466. https://doi.org/10.1002/jwmg.45

Farrell, S.L., M.L. Morrison, A.J. Campomizzi, and R.N. Wilkins. 2012. Conspecific cues and breeding habitat selection in an endangered woodland warbler. Journal of Animal Ecology 81: 1056-1064. https://doi. org/10.1111/j.1365-2656.2012.01995.x

Finity, L., and J.J. Nocera. 2012. Vocal and visual conspecific cues influence the behavior of Chimney Swifts at provisioned habitat. Condor 114: 323-328. https://doi. org/10.1525/cond.2012.110145

Government of Canada. 2017. Species profile: Barn Swallow. Accessed 20 March 2019. https://wildlife- species. canada.ca/species-risk-registry/species/species Details_e.cfm?sid=1147.

Guthery, F.S., J.J. Lusk, and M.J. Peterson. 2001. The fall of the null hypothesis: liabilities and opportunities. Journal of Wildlife Management 65: 379-384. https:// doi.org/10.2307/3803089

Hahn, B.A., and E.D. Silverman. 2006. Social cues facilitate habitat selection: American redstarts establish breeding territories in response to song. Biology Letters 2: 337-340. https://doi.org/10.1098/rsbl.2006.0472

Heagy, A., D. Badzinski, D. Bradley, M. Falconer, J. McCracken, R.A. Reid, and K. Richardson. 2014. Recovery Strategy for the Barn Swallow (Hirundo rustica) in Ontario. Ontario Recovery Strategy Series. Accessed 20 March 2019. http://files.ontario.ca/ environment-and-energy/species-at-risk/mnr_sar_rs_ brn_swl_en.pdf.

Johnson, D.H. 1999. The insignificance of statistical significance testing. Journal of Wildlife Management 63: 763-772. https://doi.org/10.2307/3802789

Kostka, K. 2000. Social attraction: a new technique for establishing a Purple Martin colony site. Purple Martin Conservation Association. Accessed 1 December 2015. http://www.purple-martin.org/PMArticles/Social AttractionPMPA.htm.

Lepage, D. 2007. Barn Swallow. Pages 398-399 in Atlas of the breeding birds of Ontario, 2001-2005. Edited by M.D. Cadman, D.A. Sutherland, G.G. Beck, D. Lepage, and A.R. Couturier. Bird Studies Canada, Environment Canada, Ontario Field Ornithologists, Ontario Ministry of Natural Resources, Ontario Nature, Toronto, Ontario, Canada. 
MECP (Ministry of Environment, Conservation and Parks. 2012. Species at risk in Ontario. Accessed 21 March 2019. https://www.ontario.ca/page/species-riskontario.

MECP (Ministry of Environment, Conservation and Parks). 2013. Alter a structure (habitat for Barn Swallow). Accessed 21 March 2019. https://www.ontario.ca/ page/alter-structure-habitat-barn-swallow.

MNRF (Ministry of Natural Resources and Forestry). 2000. Southern Ontario Land Resource Information System (SOLRIS). Accessed 21 March 2019. https:// data.ontario.ca/dataset/southern-ontario-land-resourceinformation-system-solris-20.

Møller, A.P. 1987. Advantages and disadvantages of coloniality in the swallow, Hirundo rustica. Animal Behaviour 35: 819-832. https://doi.org/10.1016/S00033472(87)80118-5

Nakagawa, S., and I.C. Cuthill. 2007. Effect size, confidence interval and statistical significance: a practical guide for biologists. Biological Reviews 82: 591-605. https://doi.org/10.1111/j.1469-185X.2007.00027.x

Nebel, S., A. Mills, J.D. McCracken, and P.D. Taylor. 2010. Declines of aerial insectivores in North America follow a geographic gradient. Avian Conservation and Ecology 5(2): 1. http://doi.org/10.5751/ACE-00391-050201

Nocera, J.J., G.J. Forbes, and L.A. Giraldeau. 2006. Inadvertent social information in breeding site selection of natal dispersing birds. Proceedings of the Royal Society of London B: Biological Sciences 273: 349-355. https://doi.org/10.1098/rspb.2005.3318

Nuzzo, R. 2014. Statistical errors: $P$ values, the "gold standard" of statistical validity, are not as reliable as many scientists assume. Nature 506: 150-152. https://doi.org/ 10.1038/506150a

Parrish, J.K., and L. Edelstein-Keshet. 1999. Complexity, pattern, and evolutionary trade-offs in animal aggregation. Science 284: 99-101. https://doi.org/10.1126/ science.284.5411.99

Peck, G.K., and R.D. James. 1987. Breeding Birds of Ontario: Nidiology and Distribution Volume 2: Passerines. The Royal Ontario Museum, Toronto, Ontario, Canada. https://doi.org/10.5962/bhl.title.60694

R Core Team. 2017. R: a language and environment for statistical computing. R Foundation for Statistical Computing, Vienna, Austria.

Reed, J.M., T. Boulinier, E. Danchin, and L.W. Oring. 1999. Informed dispersal: prospecting by birds for breeding sites. Current Ornithology 15: 189-259. https://doi.org/ 10.1007/978-1-4757-4901-4_5
Ringhofer, M., and T. Hasegawa. 2014. Social cues are preferred over resource cues for breeding-site selection in Barn Swallows. Journal of Ornithology 155: 531-538. https://doi.org/10.1007/s10336-013-1035-3

Safran, R.J. 2004. Adaptive site selection rules and variation in group size of barn swallows: individual decisions predict population patterns. American Naturalist 164: 121-131. https://doi.org/10.1086/422198

Safran, R.J. 2007. Settlement patterns of female barn swallows Hirundo rustica across different group sizes: access to colorful males or favored nests? Behavioral Ecology and Sociobiology 61: 1359-1368. https://doi.org/ 10.1007/s00265-007-0366-6

Samuel, D.E. 1971. Vocal repertoires of sympatric Barn and Cliff Swallows. Auk 88: 839-855. https://doi.org/10. $2307 / 4083842$

Sauer, J.R., W.A. Link, J.E. Fallon, K.L. Pardieck, and D.J. Ziolkowski, Jr. 2013. The North American Breeding Bird Survey 1966-2011: summary analysis and species accounts. North American Fauna 79: 1-32. https:// doi.org/10.3996/nafa.79.0001

Sauer, J.R., K.L. Pardieck, D.J. Ziolkowski, Jr., A.C. Smith, M.R. Hudson, V. Rodriguez, H. Berlanga, D.K. Niven, and W.A. Link. 2017. The first 50 years of the North American Breeding Bird Survey. Condor 119: 576-593. https://doi.org/10.1650/condor-17-83.1

Schlaepfer, M.A., M.C. Runge, and P.W. Sherman. 2002. Ecological and evolutionary traps. Trends in Ecology \& Evolution 17: 474-480. https://doi.org/10.1016/S01695347(02)02580-6

Shields, W.M., and J.R. Crook. 1987. Barn Swallow coloniality: a net cost for group breeding in the Adirondacks? Ecology 68: 1373-1386. https://doi.org/10.2307/ 1939221

Smith, A.C., M.R. Hudson, C.M. Downes, and C.M. Francis. 2015. Change points in the population trends of aerial-insectivorous birds in North America: synchronized in time across species and regions. PLoS ONE 10: e0130768. https://doi.org/10.1371/journal.pone.0130768

Ward, M.P. 2005. Habitat selection by dispersing yellowheaded blackbirds: evidence of prospecting and the use of public information. Oecologia 145: 650-657. https:// doi.org/10.1007/s00442-005-0179-0

Wasserstein, R.L., and N.A. Lazar. 2016. The ASA's statement on $p$-values: context, process, and purpose. American Statistician 70: 129-133. https://doi.org/10.1 080/00031305.2016.1154108

Received 27 March 2019

Accepted 18 December 2019 